\title{
İki farklı fotovoltaik (PV) enerji sisteminin farklı hayvancılık işletmelerinde kullanımının değerlendirilmesi
}

Evaluation of the use of two different photovoltaic (PV) energy systems in different livestock enterprises

\author{
Fatih Mehmet EMIROĞLU1(i), Ali AYBEK 2 (iD), Hamza KUZU \\ ${ }^{1}$ TKDK Kahramanmaraş il Koordinatörlüğü , 46100, Kahramanmaraş/TÜRKiYE. \\ ${ }^{2}$ Kahramanmaraş Sütçü Imam Üniversitesi, Ziraat Fakültesi, Biyosistem Mühendisliği Bölümü, 46100, Kahramanmaraş/Türkiye. \\ ${ }^{3}$ Kahramanmaraş Sütçü Imam Üniversitesi, Ziraat Fakültesi, Biyosistem Mühendisliği Bölümü, 46100, Kahramanmaraş/Türkiye.
}

\section{MAKALE BILGISI / ARTICLE INFO}

\section{Makale tarihçesi / Article history:}

DOI: 10.37908/mkutbd.957647

Geliş tarihi /Received:25.06.2021

Kabul tarihi/Accepted:10.11.2021

\section{Keywords:}

Energy, photovoltaic (PV), broiler enterprise, freshwater fish enterprise.

Corresponding author: Ali AYBEK

$\triangle$ : aaybek@ksu.edu.tr

\section{Ö Z E T / A B S T R A C T}

Atıf / Citation: Emiroğlu FM, Aybek A, Kuzu H (2021) İki farklı fotovoltaik (PV) enerji sisteminin farklı hayvancılık işletmelerinde kullanımının değerlendirilmesi. MKU. Tar. Bil. Derg. 26(3) : 808-820. DOI: 10.37908/mkutbd.957647

\section{GíRiş}

Tarım ve hayvancılık işletmelerinde enerji ihtiyacı hızlı bir şekilde artmaktadır. Bu enerji ihtiyacını karşılayabilmek için son yıllarda çiftliklerde rüzgâr ve güneş enerjisinden elektrik üretimi artmıştır. Ancak bu artış gerekli enerji ihtiyacını karşılayacak seviyeye henüz gelememiştir (Akyüz ve ark., 2009). 
Ülkemizde tüm sektörlerde olduğu gibi tarımsal işletmelerde de enerji sorununa karşı daha çok enerji üretiminin yanı sıra, kendi öz tüketimlerini karşılayabilecek enerjilerini üretecek ve şebekeden enerji taleplerini azaltacak sistemler üzerinde durulması gereklidir. Enerji maliyeti, tarım ve hayvancılık işletmelerinde en önemli maliyet kalemlerinden biridir. Bu nedenle bu enerji maliyetinin azaltılması, işletmelerin kâr paylarının artmasını sağlayacaktır (Eker ve Vardar, 2004).

Ekonomik gelişmenin merkezinde olan enerji, fosil yakıtlar gibi sınırlı kaynaklardan karşılanması durumunda enerji ithal eden ülkeler için bir güvensizlik ve aynı zamanda kalıcı bir bağımlııı da oluşturmaktadır (Karaca, 2017). Enerji ihtiyacının büyük çoğunluğunun dışa bağımlı olması, yeni enerji alternatiflerine yönelmeyi zorunlu kılmaktadır. Bu bağlamda alternatif olarak yenilenebilir enerji kaynakları kontrol edilebilir, çözümler üretilebilir olması dolayısıyla ön plana çıkmaktadır (Bilgili ve Dağtekin, 2017). Geleneksel fosil yakıtların aşırı kullanımı nedeniyle çevreye verdiği zararların önemli oranda azaltılabilmesi için de yenilenebilir enerji kaynaklarına ağırlık verilmesi ve etkin bir şekilde yararlanılması gerekmektedir. Tüm sektörlerde olduğu gibi tarım ve hayvancılık sektöründe de bu kaynakların aktif bir şekilde kullanılması gerekmektedir. Yenilenebilir enerji kaynaklarının tarım sektöründe uygulanabilirliği ve ekonomikliği ise iklim, bölge koşulları ve seçilen sisteme göre değişmektedir. Tarım ve hayvancılık sektöründe kullanılan başlıca yenilenebilir enerji sistemleri; biyokütle, jeotermal enerji, rüzgâr ve güneş enerjisi sistemleridir (Öztürk ve ark., 2010).

Gereksinim duyulan enerjiyi ithal etmek yerine mevcut yenilenebilir kaynaklardan karşılamak hem ekonomik hem de sürdürülebilir olmanın yanında çevre dostu bir seçim olacaktır (Karaca, 2019). Ülkemizde \%73 olan enerjide dışa bağımlılık oranının düşürülmesi için, 2023 yılında elektrik enerjisi üretimi içindeki yenilebilir enerji kaynakları payının en az \%30 olması hedeflenmiştir (Dağtekin, 2012). Yenilenebilir enerji kaynaklarının en bilineni ve dünyanın en büyük enerji kaynağı ise güneş enerjisidir. Güneş enerjisi, elektrik şebekesinin olmadığı, yerleşim yerlerinden uzak yerlerde ekonomik yönden uygun olarak istenen güçte kullanılabilmektedir (Dağtekin, 2012).

Türkiye, sahip olduğu coğrafi konum itibariyle, yüksek radyasyon (ışıma) oranına ve yüksek güneşlenme süresine sahiptir ve güneş enerjisi potansiyeli bakımından diğer birçok ülkeye göre şanslı durumdadır. Türkiye'nin en fazla güneş enerjisi potansiyeline sahip olan bölgeleri Güneydoğu Anadolu ve Akdeniz
Bölgeleridir (Behçet ve ark., 2013; Dağtekin ve ark., 2014).

Bu çalışmanın amacı, Kahramanmaraş ilinde bulunan iki farklı hayvancılık işletmesinde (etlik piliç ve tatlı su balık işletmesi) mevcut bulunan şebekeye bağlantılı (On-grid) ve şebekeye bağlantısız (Off-grid) fotovoltaik (PV) enerji sistemlerini karşılaştırarak benzer işletmelerde uygulanabilirliğini değerlendirmektir. Çalışmanın hedefleri ise;

- İşletmelerde enerji tüketen makine/ekipmanların belirlenmesi,

- İşletmelerin enerji gereksinimlerini karşılayacak PV sistemlerin belirlenmesi,

- Işletmelerde kullanılan PV sistemlerin maliyetlerinin belirlenmesi,

- Enerji sistemlerinin ekonomik analizlerinin yapılması, - Yenilenebilir enerji sistemlerinden yararlanmak isteyen tarımsal işletmelerde, güneş enerjisi sistemlerinin uygulanmasına yönelik öneriler geliştirmektir.

\section{MATERYAL ve YÖNTEM}

\section{Materyal}

\section{Araştırmanın yürütüldüğü bölge bilgileri}

Araştırmanın yürütüldüğü Kahramanmaraş ili, 37-38 enlem ve 36-37 boylamları arasında yer almakta olup Türkiye'nin 11. büyük ilidir ve $14346 \mathrm{~km}^{2 \prime}{ }^{\prime}$ lik yüzölçümüne sahiptir. Deniz seviyesinden yüksekliği yaklaşık 568 m'dir ve kuzeye doğru gidildikçe dağlık alanları artmaktadır. Topraklarının \%16.3'ü ovalardan, \%24'ü platolardan ve \%59.7'si ise dağlardan oluşmaktadır. Kahramanmaraş, Türkiye'nin Akdeniz, Doğu Anadolu ve Güneydoğu Anadolu bölgelerinin birbirine en yakın olduğu alanda yer aldığından dolayı, Akdeniz İklimi özellikleri görülmesine rağmen, yükseltiye bağlı olarak kuzeye doğru gidildikçe tamamen karasal iklim özellikleri görülür (Anonim, 2021a).

Türkiye Güneş Enerjisi Potansiyeli Atlası (GEPA) incelendiğinde Kahramanmaraş'ta güneyden kuzeye gidildikçe ve rakım arttıkça güneş enerjisi potansiyeli daha yüksek olmaktadır (Şekil 1). Kahramanmaraş yıllık güneşlenme süresi 2924 saat (günlük 8 saat), yıllık güneş enerjisi $1611 \mathrm{kWh} \mathrm{m}^{-2} \mathrm{yll}^{-1}$, günlük ise $4.41 \mathrm{kWh} \mathrm{m}^{-2}$ gün ${ }^{1}$ olarak belirlenmişstir. Kahramanmaraş'ın güneş enerjisi potansiyeli; aylık ortalama olarak en yüksek haziran ayında (204 kWh m ${ }^{-2}$ ) en düşük aralık ayında (56 kWh m $\left.{ }^{2}\right)$ oluşmakta ve yıllık ise toplam $1611 \mathrm{kWh} \mathrm{m}^{-2}$ olmaktadır (ETKB, 2021). 


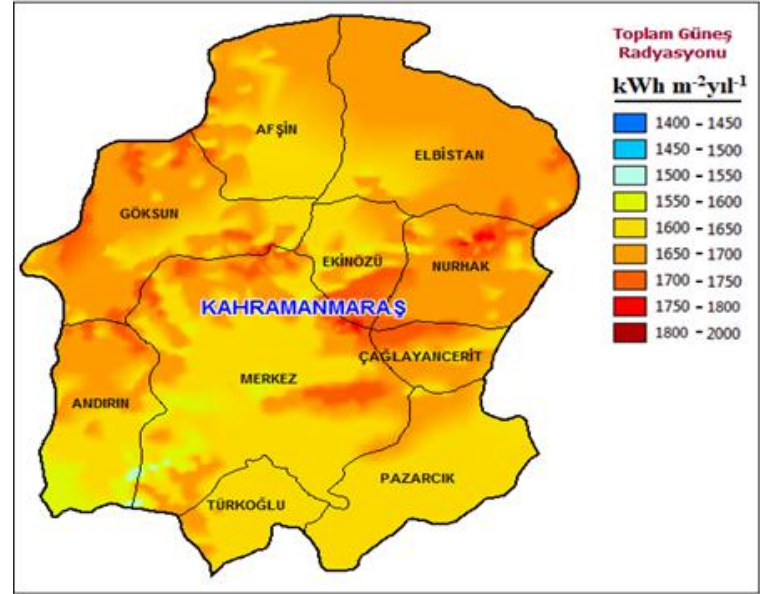

Şekil 1. Kahramanmaraş güneş enerjisi potansiyel haritası.

Figure 1. Solar energy potential map of Kahramanmaraş.

\section{işletmelerde kullanılan makine/ekipman ve PV sistem elemanları}

Çalışma, Kahramanmaraş ilinde bulunan iki farklı hayvancılık işletmesinde (etlik piliç ve tatlı su balık işletmesi) yürütülmüştür. Söz konusu işletmelere ilişkin bilgiler ile işletmelerde kullanılan makine/ekipmanlar ve PV elemanları aşağıda sunulmuştur.

\section{Etlik piliç (broiler) işletmesi elektrik tüketen makine/ekipmanları}

İşletme, Kahramanmaraş ili Türkoğlu ilçesinde faaliyet göstermekte olup 49812 adet / dönem ve 6 dönem halinde yıllık 300000 adet kapasiteye sahiptir. İşletme, elektrik enerjisinin tamamını bölgesel elektrik dağıtım şirketinden karşılamaktadır. İşletmede, şebeke bağlantıı (On-grid) PV güneş enerjisi sistemi kullanılmaktadır. Şebeke bağlantılı (On-grid) fotovoltaik sistemler, üretilen elektriğin akülerde depolanması yerine üretim yerinde tüketilmesi prensibi ile çalışmaktadır. Üretilen fazla enerji elektrik şebekesine verilmekte, yeterli enerjinin üretilmediği durumlarda ise şebekeden enerji alınmaktadır. Böyle bir sistemde enerji depolamasına gerek bulunmamaktadır, yalnızca üretilen DC (Doğru Akım) elektriğin, AC (Alternatif Akım) elektriğe çevrilmesi ve şebeke uyumlu olması yeterlidir. İşletmede elektrik tüketen makine ve ekipmanlar Çizelge 1'de gösterilmiştir.

Çizelge 1. Etlik piliç işletmesinde elektrik tüketen makine ve ekipmanlar

Table 1. Machines and equipment consumed electricity in the broiler enterprise

\begin{tabular}{lcc}
\hline Elektrik tüketen makine/ekipmanlar & Güç (kW) & Sayı (Adet) \\
\hline Otomatik yemleme sistemi motor grubu & 0.55 & 4 \\
Kümeslerde otomatik silo sistemi & 0.55 & 2 \\
Sulama sistemi motor grubu & 1.10 & 1 \\
Havalandırma fanı 1 (çap:138 cm, debi: $37.85 \mathrm{~m}^{3} \mathrm{~h}^{-1}$ ) & 1.10 & 24 \\
Havalandırma fanı 2 (çap: $95 \mathrm{~cm}$, debi: $11.95 \mathrm{~m}^{3} \mathrm{~h}^{-1}$ ) & 0.37 & 14 \\
Klape motoru & 0.37 & 4 \\
Soğutma pedi motor grubu (redüktörlü) & 0.55 & 4 \\
Köpüklü temizlik makinesi & 5.50 & 1 \\
Üflemeli soba & 7.50 & 2 \\
Aydınlatma sistemi (tasarruflu lambalar) & 0.023 & 200 \\
\hline
\end{tabular}

\section{Etlik piliç (broiler) işletmesi PV sistem elemanları}

Etlik piliç PV sistemi ekipmanları belirlenirken, işletmenin tam kapasite ile tüm makine ve ekipmanlarının çalışığı varsayılmıştır. PV panellerinin uygulaması, çatı konstrüksiyonu ve statik hesapları uygun olarak projelendirilen, işletmenin çatısına yapılmıştır. Çatıya uygulanan sistemlerde yer uygulamalarında kullanılan beton ayak veya çakmalı kazık konstrüksiyonu bulunmadığından, yerde uygulanan sistemlere göre daha uygun maliyete sahip olmaktadır. Tesisin ihtiyacını karşılamak için $270 \mathrm{~W}$ değerinde PV panelleri, 30 kW'lık invertörler ve çift yönlü sayaç kullanılmıştır. Sistemde kullanılan diğer ekipmanlar; bağlantı elemanları, kablolar ve sigortalardır. Şebekede oluşabilecek arıza ve elektrik kesintilerine karşı sistemde ayrıca dizel jeneratör de bulunmaktadır. Bu tesiste kullanılan ekipmanların özelliklerine aşağıda ayrıntılı olarak değinilmiştir.

\section{PV panel}

$\mathrm{Bu}$ uygulama için polikristal silikon hücre tipli SOLARTURK STR 60 P 270 model güneş paneli kullanılmıştır. Sistemde kullanılan PV panellerin bir tanesinin anma gücü $270 \mathrm{~W}$, yüzey alanı $1.62 \mathrm{~m}^{2}$ ve verimi \%15.4'tür.

\section{invertör}

İşletmede bağımsız MPPT (Maksimum Güç Noktası Takipçisi) özelliği ile farklı değerlerde veya sayıda solar 
paneller ile kolayca uygulama yapabilme özelliği olan tam sinüs şebeke frekansına uyumlu bir invertör kullanılmıştır. İşletmede kullanılan panellerin üreteceği elektrik enerjisi değerlerini karşılayabilmesi için $30 \mathrm{~kW}$ değere sahip 10 adet HUAWEI SUN2000-33KTL-A model invertör kullanılmıştır. Toplam invertör gücü 300 kW'tır. İnvertör üzerinde dâhili DC kesici hem DC hem de AC tarafta tip II yıldııım koruyucular ve kaçak akım koruması bulunmaktadır.

\section{Diğer ekipmanlar}

Sistemde $6 \mathrm{~mm}$ çapında $2500 \mathrm{~m}$ solar kablo, güneş panelleri arasındaki kablo bağlantıları için galvanizli kablo kanalları, çift yönlü sayaç, trafo, kaçak akım devre kesici, sigorta ve bağlantı elemanları kullanılmıştır. Ayrıca sistemin çalışmasının ve üretim verilerinin izlenebilmesi için invertör üreticisi firma tarafından oluşturulan yazılım sistemi ile tesiste üretilen güneş enerjisi elektriğinin verileri anlık, günlük ve aylık olarak bilgisayarlardan ya da cep telefonundan takip edilebilmektedir. Etlik piliç işletmesinde PV güneş panellerinde üretilen elektrik enerjisi doğrudan şebekeye aktarıldığından, sistem içerisinde akü grubu bulunmamaktadır. Bu da maliyeti oldukça avantajlı hale getirmektedir.

\section{Tatlısu balık işletmesi elektrik tüketen makine/ekipmanlar}

Kahramanmaraş Menzelet Baraj Gölü üzerinde faaliyet gösteren işletme, 30 ton $\mathrm{yıl}^{-1}$ kapasiteli olup ayrıca 1000000 adet $\mathrm{yll}^{-1}$ yavru üretimi gerçekleştirmektedir. İşletmenin elektrik şebeke bağlantısı olmadığı için elektrik enerjisi ihtiyacı, dizel jeneratörden karşılanmaktadır. Ancak jeneratör maliyetlerinin fazla olmasından dolayı hâlihazırda elektrik enerjisinin tamamı yenilenebilir enerji kaynağı olan PV sistemlerden karşılanmaktadır. Elektrik ihtiyacının olduğu ancak şebeke elektriğinin olmadığı bu gibi yerlerde, çözüm olarak Off-grid sistem olarak adlandırılan ve enerjinin depolanması için akü grubunun sisteme dâhil edildiği PV sistemleri kullanılmaktadır.

İsletmede kullanılan ve elektrik tüketen makine ve ekipmanlar Çizelge 2'de gösterilmiştir.
Çizelge 2. Tatlı su balık işletmesinde elektrik tüketen makine ve ekipmanlar

Table 2. Machines and equipment consumed electricity in the freshwater fish enterprise

\begin{tabular}{lcc}
\hline Makine/ekipman & Güç (kW) & Sayı (Adet) \\
\hline Sirkülasyon pompası 1 & 2.20 & 3 \\
Sirkülasyon pompası 2 & 0.50 & 2 \\
Isı pompası & 1.00 & 3 \\
Havalandırma pompası & 0.50 & 2 \\
Buzdolabı & 0.20 & 1 \\
Çamaşır makinesi & 2.20 & 1 \\
Elektrikli ocak & 2.00 & 1 \\
Led projektör & 0.05 & 3 \\
\hline
\end{tabular}

\section{Tatlı su balık işletmesi PV sistem elemanları}

İşletmede tesisin elektrik ihtiyacını karşılamak için $255 \mathrm{~W}$ değerinde PV paneller, 5 kW'lık invertörler ve 2V 1200 Ah'lik akü grubu kullanılmıştır. Sistemde kullanılan diğer ekipmanlar; bağlantı elemanları, kablolar ve sigortalardır. Sistemde oluşabilecek sorun ve arızalarda ise dizel jeneratör devreye girebilmektedir. Tesiste kullanılan bu ekipmanların özelliklerine aşağıda ayrıntılı olarak değinilmiştir.

\section{PV panel}

$\mathrm{Bu}$ tesiste üretilen fazla elektrik enerjisi akülerde depolanmaktadır. Üretilen elektrik enerjisi değeri güneşlenme süresine ya da mevsimlere göre değişmektedir. İşletmenin günlük enerji ihtiyacının karşılanabilmesi için güneşlenmenin en az olduğu kış ayları temel alınarak CSUN CSUN255-60P model PV panel seçilmiştir. PV panelinin anma gücü $255 \mathrm{~W}$, yüzey alanı $1.62 \mathrm{~m}^{2}$ ve verimi \%15.4'tür.

\section{invertör}

Şebekeden bağımsız akülü bir sistemde doğru akım enerjisinin alternatif akım enerjisine çevrilmesine yarayan invertörün gücü ve seçimi yapılırken, PV sistemde kullanılacak makine ve ekipmanlardan aynı anda kaç tanesinin çalışabileceği ve toplam güç değerleri dikkate alınmaktadır. Tatlı su balık işletmesinde sistemin aynı anda ortalama 15 kW'lık kısmının çalıştığı ve 15 kW'lık invertörün yeterli olacağı öngörülmüştür.

Araştırma konusu işletmede tam sinüs dalga şebeke frekansına uyumlu ve ileride sisteme entegre edilmesi düşünülen rüzgâr türbini ile de senkronize olabilecek MexxSUN HIO $5000 \mathrm{~W}$ model bir hibrit invertör tercih edilmiștir. Hibrit invertörler çift yönlü olup, üretilen enerjinin fazlalığı veya azlığına göre elektriğin akülere veya sisteme verilmesini sağlamaktadır. Bu yönü ile güneş panellerinden gelen veya rüzgâr türbininde üretilecek elektrik enerjisinin akülere depolanması 
sırasında ortaya çıkabilecek uyum sorunlarının ortadan kaldırılması hedeflenmiştir.

\section{Şarj regülatörü}

Şarj regülatörleri, güneş enerjisinden gelen akımı ve voltajı dengelemekte, akülerin fazla şarj olmasını ve gece akülerden panellere akım gitmesini engellemektedir. Şarj regülatörlerinin boyutu, güneş panelinin akımına ve sistemde kullanılan toplam güneş panelinin gücüne göre belirlenir ve şebekeden bağlantısız (Off-grid) sistemler için tasarımda mutlaka bulunması gerekmektedir.

Tatlı su balık işletmesinde, güneş paneli gücü ve akülerin gerilim değerlerine uygun olarak verim değeri yüksek olan MPPT şarj regülatörleri tercih edilmiştir.

\section{Akü grubu}

Tatlı su balık işletmesi tesisinde derin deşarj yapılabilen, uzun süreli kullanımlara uygun, şarj edilmesi kolay özelliklere sahip yapılarından dolayı endüstriyel tip akü olarak bilinen traksiyoner tip akü kullanılmıştır. Traksiyoner aküler $\% 80$ oranında deşarj sağlayabildiğinden dolayı "derin deşarj" aküleri olarak da bilinirler. Jel veya sıvı elektrolitli olarak ikiye ayrılan traksiyoner aküler, istenilen voltaj değerine göre $2 \mathrm{~V}^{\prime}$ luk hücrelerin seri olarak bağlanmasıyla elde edilirler. Asit ve darbelere dayanıklı kaplamaya sahip ve uzun ömürlü olan bu aküler $10 \mathrm{~kg}$ ağırlığında olabilmektedirler (Anonim, 2021b).

Şebekeden bağımsız bir yenilenebilir enerji tesisinde kullanılacak akülerin kapasitesi ve sayısı belirlenirken, sistemdeki panellerin güneş göremeyeceği gün veya saat dikkate alınmaktadır. Tesise ilerleyen zamanlarda rüzgâr enerjisi sistemi dâhil edileceğinden, aküler 1 günlük enerjiyi depolayacak şekilde belirlenmiştir. Sistemde $2 \mathrm{~V}$ 1200 Ah'lik 96 adet akü grubu kullanılmıştır.

\section{Diğer ekipmanlar}

Sistemde $6 \mathrm{~mm}$ çapında $500 \mathrm{~m}$ solar kablo, güneş panelleri arasındaki kablo bağlantıları için galvanizli kablo kanalları, kaçak akım devre kesici, sigorta ve bağlantı elemanları kullanılmıştır. Akülü sisteme sahip işletmede, panellerde üretilen elektrik enerjisini aktarmak için DC kablo, akü bağlantı kabloları ve akü sonrası için AC kablolar kullanılmıştır.

\section{Dizel jeneratör}

Tatlısu balık işletmesinde şehir elektrik şebekesi bulunmadığından, PV güneş enerjisi sistemi kurulmadan önce elektrik enerjisi 20 kVA'lık dizel jeneratör ile karşılandığı bildirilmiştir. Ancak PV sistem kurulumundan sonra dizel jeneratör sadece PV sisteminde arıza olması durumunda devreye girecek şekilde bağlantısı yapılmıştır.

\section{Yöntem}

Araştırmada, ilk olarak her iki işletmenin kurulu güçlerine göre elektrik enerjisi gereksinimleri belirlenmiştir. İkinci olarak işletmelerin PV sistemi tasarımları üzerinde durularak, sistem gereksinimlerine uygun seçilmiş olan PV ekipmanları ve özellikleri incelenmiştir. Daha sonra her iki işletme için ayrı ayrı PV sistemlerin optimum maliyetleri belirlenmiştir. İşletmelerin başa başnoktaları ve kâra geçiş sürelerini belirleyebilmek için, PV sistem kurulumu öncesi elektrik enerjisi maliyetleri ortaya konulmuştur. Son olarak da işletmelerin elektrik enerjisi maliyetleri ile PV sistem maliyetlerinin karşılaştırılması yapılarak, hayvancılık işletmelerinde kullanımının değerlendirilmesi ve ekonomik analizi yapılmıştır.

Elektrik şebekesi enerji maliyetlerine esas olması açısından vergi ve fonlar dahil fiyat $1.059 \mathrm{TL} \mathrm{kWh}^{-1}$ (EPDK, 2021), dizel jeneratör akaryakıt maliyeti için ise nakliye hariç Haziran 2021 dizel akaryakıt fiyat ortalaması 7.3 TL $\mathrm{L}^{-1}$ temel alınmıştır. Güneş enerjisi sistemlerinde kullanılan PV sistem elemanlarının fiyatları, marka seçimine ve ihtiyaç duyulan teknik özelliklere göre değişiklik göstermektedir. Ayrıca PV sistem elemanlarının büyük çoğunluğu yurtdışında üretildiği için döviz bazında fiyatlandırımaktadır. Araştırma konusu işletmeler PV güneş enerjisi sistemleri için bire bir görüşme ve pazarlıklarla, kendilerine özgü fiyat teklifleri almışlardır. Bu nedenle işletmelerin maliyet analizleri almış oldukları bu tekliflere uygun olarak yapılmıştır. Ancak işletmelerine PV sistem kurmak isteyen yatırımcılara fikir vermesi açısından güncel piyasa koşullarına uygun yaklaşık maliyet cetveli de çalışma içerisinde sunulmuştur.

\section{BULGULAR ve TARTIŞMA}

Çalışmanın bu bölümünde Kahramanmaraş ilinde bulunan iki farklı hayvancılık işletmesinin (etlik piliç ve tatı su balık işletmesi) enerji gereksinimleri, enerji gereksinimlerine uygun $\mathrm{PV}$ güneş enerjisi sistem tasarımları ve kurulan PV sistemlerinin maliyet analizlerine yer verilmiştir.

Araştırma bulguları üç bölümden oluşmaktadır. Birinci bölümde işletmelerin enerji gereksinimleri, ikinci bölümde etlik piliç işletmesi enerji gereksinimlerine uygun PV sistemleri ve maliyet analizi, üçüncü bölümde tatlı su balık işletmesi enerji gereksinimlerine uygun PV sistemleri ve maliyet analizi yapılmıştır. Maliyet analizleri yapılırken işletmelerin PV sistem öncesi ve sonrası elektrik enerjisi maliyetlerinin karşılaştırması ve başa 
başnoktalarının belirlenmesi üzerinde durulmuştur.

\section{İşletmelerin enerji gereksinimleri}

Bir işletmenin enerji ihtiyacını ortaya koyabilmek için öncelikle söz konusu işletmede kullanılan ekipmanların enerji tüketim değerlerinin belirlenmesi gerekmektedir. Araştırmada ele alınan etlik piliç işletmesindeki ekipmanlar ve elektrik enerjisi değerleri Çizelge 3'te, tatlı su balıkçılık işletmesindeki ekipman ve elektrik enerjisi tüketim değerleri Çizelge 4'te verilmiştir.

Çizelge 3. Etlik piliç işletmesindeki ekipmanlar ve elektrik enerjisi tüketimi

Table 3. Equipment and electrical energy consumption in the broiler enterprise

\begin{tabular}{|c|c|c|c|c|c|}
\hline Cihazlar & $\begin{array}{c}\text { Güç } \\
(k W)\end{array}$ & $\begin{array}{l}\text { Miktar } \\
\text { (Adet) }\end{array}$ & $\begin{array}{l}\text { Toplam güç } \\
\text { gereksinimi } \\
(\mathrm{kW})\end{array}$ & $\begin{array}{l}\text { Çalışma } \\
\text { süresi } \\
\left(\text { h gün }{ }^{-1}\right)\end{array}$ & $\begin{array}{l}\text { Toplam enerji } \\
\text { tüketimi } \\
\left(\mathrm{kWh} \text { gün }{ }^{-1}\right)\end{array}$ \\
\hline Otomatik yemleme sistemi motor grubu & 0.55 & 4 & 2.20 & 6 & 13.20 \\
\hline Kümeslerde otomatik silo sistemi & 0.55 & 2 & 1.10 & 6 & 6.60 \\
\hline Sulama sistemi motor grubu & 1.10 & 1 & 1.10 & 20 & 22 \\
\hline Havalandırma fanı $1\left(\phi 138 \mathrm{~cm}, \mathrm{Q} 37850 \mathrm{~m}^{3} \mathrm{~h}^{-1}\right)$ & 1.10 & 24 & 26.40 & 20 & 528 \\
\hline Havalandırma fanı $2\left(\phi 95 \mathrm{~cm}, \mathrm{Q} 11950 \mathrm{~m}^{3} \mathrm{~h}^{-1}\right)$ & 0.37 & 14 & 5.18 & 10 & 51.80 \\
\hline Klape motoru & 0.37 & 4 & 1.48 & 1 & 1.48 \\
\hline Soğutma pedi motor grubu & 0.55 & 4 & 2.20 & 8 & 17.60 \\
\hline Köpüklü temizlik makinesi & 5.50 & 1 & 5.50 & 0.50 & 2.75 \\
\hline Üflemeli soba & 7.50 & 2 & 15 & 8 & 120 \\
\hline Aydınlatma sistemi (tasarruflu lambalar) & 0.023 & 200 & 4.60 & 24 & 110.40 \\
\hline Toplam & & & 64.76 & & 873.83 \\
\hline
\end{tabular}

Etlik piliç işletmesindeki ekipmanların tam kapasite ile çalışması durumunda saatlik toplam güç gereksinimi $64.76 \mathrm{~kW}$, işletmede kullanılan ekipmanların günlük çalışma süreleri dikkate alındığında toplam günlük enerji gereksinimi ise $873.83 \mathrm{kWh}$ gün $^{-1}$ olarak belirlenmiştir (Çizelge 3).

Etlik piliç işletmesinde güneş enerjisi sisteminin kapasitesi belirlenirken, işletmenin saatlik ve günlük maksimum enerji gereksinimleri dikkate alınmıştır. Ancak işletme koşullarına ve etlik piliç üretim dönemlerine göre bu değerler farklı çıkabilmektedir.
Örneğin üretim dönemi başlangıcında küçük olan civcivler için havalandırma fanları yarı zamanlı çalışırken, üretimin sonuna doğru kademeli bir şekilde artarak çalışmaya devam etmektedirler. Üflemeli soba kış aylarında tam kapasite çalışırken, yaz aylarında ise her dönem 10 gün çalışmaktadır. Aynı şekilde köpüklü temizlik makinesi her üretim döneminde (40 gün) sadece 2 saat çalışmaktadır. Burada unutulmaması gereken nokta Çizelge 3'te yer alan ekipmanların tamamının aynı anda çalışmadığı gerçeğidir.

Çizelge 4. Tatlı su balıkçılık işletmesindeki ekipmanlar ve elektrik enerjisi tüketimi

Table 4. Equipment and electrical energy consumption in the freshwater fish enterprise

\begin{tabular}{lccccc}
\hline Cihazlar & Güç $(\mathrm{kW})$ & Adet & $\begin{array}{c}\text { Saatlik güç } \\
\text { gereksinimi } \\
(\mathrm{kWh})\end{array}$ & $\begin{array}{c}\text { Çalışma } \\
\text { süresi } \\
(\mathrm{h})\end{array}$ & $\begin{array}{c}\text { Günlük enerji } \\
\text { tüketimi } \\
\text { (kWh gün }\end{array}$ \\
\hline Sirkülasyon pompası 1 & 2.2 & 3 & 6.6 & 24 & 158.4 \\
Sirkülasyon pompası 2 & 0.5 & 2 & 1 & 1 & 1 \\
Isı Pompası & 1 & 3 & 3 & 8 & 24 \\
Hava pompası & 0.5 & 2 & 1 & 24 & 24 \\
Buzdolabı & 0.2 & 1 & 0.20 & 8 & 1.6 \\
Çamaşır makinesi & 2.2 & 1 & 2.20 & 1 & 2.2 \\
Elektrikli ocak & 2 & 1 & 2 & 10 & 20 \\
Led projektör & 0.05 & 3 & 0.15 & 8 & 1.2 \\
Toplam & & & 16.15 & & 232.4 \\
\hline
\end{tabular}


Çizelge 4'te kurulu güç değeri verilen tatlı su balıkçılık işletmesi için kurulması gereken PV güneş enerjisi sisteminin, saatlik $16.15 \mathrm{kWh}$ ve çalışma süreleri dikkate

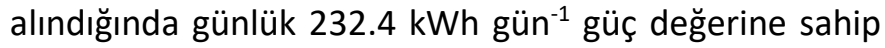
olması gerektiği düşünülebilir. Ancak yine unutulmaması gereken nokta, Çizelge 4'te yer alan cihazların tamamının aynı anda çalışmadığı ve dönemsel olarak farklılık gösterebileceğidir.

Araştırma konusu tarımsal işletmelerin her ikisinde de tam kapasitede çalışması durumda gerekli olacak elektrik enerjisi değerlerine göre PV sistemi tasarımı yapılmıştır. İşletmelerin gerçekte bu değerlere çoğu zaman ulaşamayacakları bilinmektedir.

\section{Etlik piliç işletmesinin PV sistemi ve maliyet analizi}

Şebeke bağlantılı (On-grid) fotovoltaik sistemler, üretilen elektriğin akülerde depolanması yerine üretim yerinde tüketilmesi prensibine dayalı olarak çalışmaktadır. Ongrid sistemlerde üretilen fazla enerji elektrik şebekesine verilir, yeterli enerjinin üretilmediği durumlarda ise şebekeden enerji alınır. Şebeke bağlantılı sistemde enerjinin depolamasına gerek yoktur, sadece üretilen DC elektriğin, AC elektriğe çevrilmesi ve şebekeye uyumlu hale gelmesi gerekmektedir. Üretilen enerji invertörler yardımı ile şehir şebeke sistemine bağlanır. Böylece panellerden üretilen enerji doğrudan şebeke sistemine gönderilmiş olur. Alan ve ışınım koşulları uygun olduğu takdirde şebekeye bağlı elektrik üretim sistemi ile istenilen güçte elektrik enerjisi üretimini sağlamak mümkündür (Anonim, 2021c).

On-grid sistemin temel bileşenleri;

- Fotovoltaik panel

- Invertör

- Trafo, çift yönlü sayaç, sigortalar, kablo ve bağlantı elemanlarıdır.

Etlik piliç işletmesi 49812 adet / dönem ve 6 dönem halinde yıllık 300000 adet kapasiteye sahiptir. İşletme elektrik enerjisinin tamamını bölgesel elektrik dağıtım şirketinden karşılamaktadır. Tam kapasite ile tüm makine ve ekipmanlar çalıştığı varsayıldığında işletmenin günlük enerji ihtiyacı $873.83 \mathrm{~kW}$ olarak belirlenmiştir (Çizelge 3). Bir etlik piliç işletmesinde iki ana gider bulunmaktadır. Bunlar yem gideri ve enerji gideridir. Yem gideri civciv temin edilen işletmelerden karşılandığından, geriye sadece elektrik enerjisi gideri kalmaktadır. Bu nedenle işletmede elektrik enerjisi maliyetini azaltmak, hatta bu sistemden gelir elde etmek için güneş enerjisi (PV) sistemi kurulmuştur. Çatı konstrüksiyonu ve statik hesaplamalar uygun olduğundan sistem çatıya kurulmuştur.

GEPA'ya göre Kahramanmaraş'ın günlük ortalama güneşlenme süresi 8 saat, günlük gelen güneş enerjisi $4.41 \mathrm{kWh} \mathrm{m}^{-2}$ olduğu bildirilmektedir. Ancak bu değerler havanın temiz, güneş açısının dik olduğu ve gölgelenmenin olmadığı zamanlar için geçerlidir. Bu sebeple kayıpların yaşanacağı ve güneşlenme süresinin çok daha az olacağı kış ayları da dikkate alınarak günlük $873.83 \mathrm{~kW}$ enerji gereksinimi olan tesisin ihtiyacını karşılamak için DC 300 kWh'lik üretim yapan bir güneş paneli (PV) sistemi, işletme tarafından kullanılmıştır. Tesiste, güneşlenme süresinin en az olduğu kış ayları temel alınarak, günlük ortalama 5 saat güneş aldığı kabul edilirse $1500 \mathrm{~kW}$ gün-1 $(300 \times 5)$ enerji elde edilmesi beklenmektedir. $\mathrm{Bu}$ enerji ihtiyacının karşılanabilmesi için 1200 adet $270 \mathrm{~W}$ değerinde polikristal güneş paneli ve 10 adet 30 kW' $ı$ k invertör kullanılmıştır. Sistemde ayrica $2500 \mathrm{~m} 6 \mathrm{~mm}$ solar kablo, $750 \mathrm{~m} 5 \times 25 \mathrm{~mm}$ NYY bağlantı kablosu, 400 kVA trafo, çift yönlü sayaç, kaçak akım rölesi, sigorta ve bağlantı elemanları kullanılmıştır. Ayrıca şebekede oluşabilecek arıza ve elektrik kesintilerine karşı 125 kVA gücündeki dizel jeneratör de sistemde bulunmaktadır.

Etlik piliç işletmesi PV sisteminde kullanılan ekipmanların, 300 kWh'lik enerji üretebilen sistem için, maliyetleri Çizelge 5 'te gösterilmiştir.

Çizelge 5. Etlik piliç işletmesi PV sisteminde kullanılan ekipmanların maliyetleri

Table 5. Cost of the equipment used in the broiler enterprise PV system

\begin{tabular}{lcccc}
\hline PV sistem elemanı & Özellikler & $\begin{array}{c}\text { Miktar } \\
\text { (Adet) }\end{array}$ & $\begin{array}{c}\text { Birim fiyat } \\
(\$)\end{array}$ & $\begin{array}{c}\text { Toplam fiyat } \\
\text { (\$) }\end{array}$ \\
\hline Güneş paneli & Polikristal 270 W & 1200 & 110 & 132000 \\
Invertör & $30 \mathrm{~kW}$ & 10 & 4500 & 45000 \\
$\begin{array}{l}\text { Trafo, çift yönlü sayaç, sigortalar, kablo, } \\
\text { bağlantı elemanları ve diğer giderler }\end{array}$ & $\begin{array}{c}\text { On-grid sisteme } \\
\text { uyumlu }\end{array}$ & 1 grup & 35000 & 35000 \\
Toplam maliyet & & & & \\
\hline
\end{tabular}

PV sistem elemanları için piyasada çok farklı marka mevcuttur ve farklı fiyatlar oluşabilmektedir. Etlik piliç işletmesi anahtar teslim PV güneş enerjisi maliyeti
210000 \$ olmuştur. Yeni kurulacak tesislerde örnek teşkil etmesi açısından piyasada uygulanan fiyatlar Çizelge 6 'da belirtilmiştir. 
Çizelge 6. PV güneş enerjisi sistemleri için piyasa ortalama maliyet tablosu (Anonim, 2021d)

Table 6. Market average cost table for PV solar energy systems

\begin{tabular}{ll}
\hline PV sistem elemanı & \multicolumn{1}{c}{ Fiyat } \\
\hline Güneş paneli & $0.40-0.70 \$ \mathrm{~W}^{-1}$ \\
Invertör & $0.15-0.25 \$ \mathrm{~W}^{-1}$ \\
Konstrüksiyon & $0.15-0.25 \$ \mathrm{~W}^{-1}$ \\
Kablo kanalı & $15-20 \mathrm{TL} \mathrm{m}^{-1}$ \\
Solar kablo $(6 \mathrm{~mm})$ & $2-5 \mathrm{TL} \mathrm{m}^{-1}$ \\
Tek veya çift yönlü sayaç & $500-1500 \mathrm{TL}^{-1} \operatorname{adet}^{-1}$ \\
Enerji nakil hattı ve trafo & $100000-200000 \mathrm{TL}^{-}$ \\
Nakliye, iş̧ilik ve diğerleri & $150000-200000 \mathrm{TL}$ \\
Projelendirme ve izin maliyetleri & $40000-60000 \mathrm{TL}$ \\
\hline
\end{tabular}

Her ürün için birim fiyatlar olmasına karşın toplu alım ve büyük işletmelerde Watt (W) başına fiyat alınmaktadır. PV panel sistemi elektrik enerjisi ürettiği sürece işletme bunu kullanacaktır.

İşletmede güneş enerjisi sistemi kurulmadan önce enerji ihtiyacının şebekeden karşılandığı bildirilmiştir. Tesiste bulunan tüm makinelerin çalıştığı bir günde $873.83 \mathrm{~kW}$ elektrik enerjisi maliyeti olmaktadır. Şebeke enerji maliyetlerine esas olması için EPDK Nisan 2021 tarifesi referans alınmıştır (EPDK, 2021). Buna göre tesiste günlük maliyet 925.39 TL $(873.83 \times 1.059)$ olmaktadır. İşletmenin tam kapasite ile yıl boyu çalıştı̆̆ı varsayıldı̆ıında; yıllık maliyet 337766 TL (365 x 925.39) olmaktadır. Ancak elektrik enerjisi tüketiminin üretim dönemlerine göre değişiklik göstermesinin yanı sıra, tüm makine ve ekipmanların aynı anda çalışmadığı bilinmektedir. Bu nedenle maliyet analizinin daha kesin sonuç vermesi açısından işletmenin son bir yıl içerisinde kullandığı elektrik enerjisi miktarı (Çizelge 7) referans alınmıştır.

Çizelge 7. Etlik piliç işletmesinin bir yıllık kullanılan elektrik enerjisi değerleri

Table 7. Electric energy values used for one year of the broiler enterprise

\begin{tabular}{lcccc}
\hline Tüketim ayı & $\begin{array}{c}\text { Aylık tüketim } \\
(\mathrm{kW})\end{array}$ & $\begin{array}{c}\text { Günlük tüketim } \\
(\mathrm{kW})\end{array}$ & $\begin{array}{c}\text { Birim fiyat } \\
(\mathrm{kWh} \mathrm{TL})\end{array}$ & $\begin{array}{c}\text { Toplam tutar } \\
(\mathrm{TL})\end{array}$ \\
\hline Nisan 20 & 13500 & 450 & 0.798 & 10773.00 \\
Mayıs 20 & 9600 & 320 & 0.798 & 7660.80 \\
Haziran 20 & 13450 & 448 & 0.798 & 10733.10 \\
Temmuz 20 & 11250 & 375 & 0.798 & 8977.50 \\
Ağustos 20 & 7180 & 239 & 0.798 & 5729.64 \\
Eylül 20 & 10760 & 359 & 0.798 & 8586.48 \\
Ekim 20 & 11420 & 381 & 0.840 & 9592.80 \\
Kasım 20 & 12700 & 423 & 0.840 & 10668.00 \\
Aralık 20 & 3900 & 0.840 & 7551.60 \\
Ocak 21 & 8990 & 313 & 1.059 & 9954.60 \\
Şubat 21 & 9400 & 388 & 1.059 & 12337.35 \\
Mart 21 & 11650 & 407 & 1.059 & 12919.80 \\
Yıllık toplam & 12200 & & & 115484.67 \\
\hline
\end{tabular}

Etlik piliç işletmesi PV sistemde üretilen ve işletmenin AKEDAŞ'a kestiği faturalar Çizelge 8'de gösterilmiştir. Bu faturalar, işletmenin kullandığı elektrik enerjisi miktarları dışında kullanım fazlası elektrik enerjisi miktarını göstermekte olup bu miktar işletmeye net gelir olarak yansımaktadır. 
Çizelge 8. Etlik piliç işletmesi PV sistemde üretilen elektrik enerjisi tablosu Table 8. Electric energy table produced in the broiler enterprise PV system

\begin{tabular}{lccccc}
\hline Üretim ayı & $\begin{array}{c}\text { Aylık üretim } \\
(\mathrm{kW})\end{array}$ & $\begin{array}{c}\text { Günlük üretim } \\
(\mathrm{kW})\end{array}$ & $\begin{array}{c}\text { Saatlik üretim } \\
(\mathrm{kWh})\end{array}$ & $\begin{array}{c}\text { Birim fiyat } \\
\left(\mathrm{kWh} \mathrm{TL}^{-1}\right)\end{array}$ & $\begin{array}{c}\text { Toplam tutar } \\
(\mathrm{TL})\end{array}$ \\
\hline Nisan 20 & 37652 & 1255.07 & 179.29 & 0.910 & 34263.32 \\
Mayıs 20 & 46970 & 1565.66 & 223.66 & 0.921 & 43259.37 \\
Haziran 20 & 35290 & 1176.33 & 168.04 & 0.905 & 31937.45 \\
Temmuz 20 & 38190 & 1273.00 & 181.85 & 0.911 & 34791.09 \\
Ağustos 20 & 17380 & 579.33 & 82.76 & 0.959 & 16667.42 \\
Eylül 20 & 25500 & 850.00 & 121.43 & 0.996 & 25398.00 \\
Ekim 20 & 15750 & 525.00 & 75.00 & 1.045 & 16458.75 \\
Kasım 20 & 16080 & 536.00 & 76.57 & 1.055 & 16964.40 \\
Aralık 20 & 15360 & 512.00 & 73.14 & 1.022 & 15697.92 \\
Ocak 21 & 16630 & 554.33 & 79.20 & 0.982 & 16330.66 \\
Şubat 21 & 26980 & 899.33 & 128.48 & 0.942 & 25415.16 \\
Mart 21 & 34720 & 1157.33 & 165.33 & 1.016 & 35275.52 \\
Toplam & 326502 & & & & 312459.06 \\
\hline
\end{tabular}

İşletmenin kullandığı elektrik enerjisi miktarı 132100 kW karşılığı 115484.67 TL ve yıllık PV sistemden elde edilen gelir 326502 kW karşılığı 312459.06 TL olarak belirlenmiştir. İşletme yıllık ortalama $115484.67 \mathrm{TL}$ olan elektrik enerjisi maliyetini sıfırlamış ve PV sistemden yaklaşı $312459.06 \mathrm{TL} \mathrm{yıl}^{-1}$ gelir sağlamıştır (Çizelge 8). Bu sonuca göre işletmenin yıllık ortalama 428000 TL kâr elde ettiği söylenebilir.

PV güneş enerjisi tesisinin maliyetinin 210000 \$ olduğu bilinmektedir. Haziran 2021 dolar kuru ortalama $8.60 \mathrm{TL}$ olduğu düşünüldüğünde, 1806000 TL (210000 x 8.60) sistem maliyeti bulunmuştur. Bu şartlarda PV sisteminin 4.2 yılda (1806000 / 428000) başa başnoktasını yakaladığı ve kendisini amorti ettiği hesaplanmıştır. Araştırmada işletmenin kullandığı elektrik enerjisi maliyeti ve PV sistemin maliyetinin işletmeye geri dönüşümü hesaplandığından, amortisman giderleri göz ardı edilmiştir.

Şebeke bağlantılı PV güneş enerjisi sistemlerinde gelir ve kazanç hesaplamaları için yapılan çalışmalarda 300 kWh'lik bir tesisin kurulum maliyeti $320000 \$$ olarak bulunmuştur. Akdeniz Bölgesi için ilk yıl ortalama getirisi ise 60000 \$ olarak belirtilmiştir. 2016 yılı verilerine göre 300 kWh'lik bir güneş enerjisi sisteminin 5.3 yılda kendisini amorti ettiği bildirilmiş̧ir (Anonim, 2021e). Araştırma konusu olan etlik piliç işletmesinin kurulum maliyeti 210000 \$ ve sistemin geri ödeme süresinin ise yaklaşık 4 yıl olduğu görülmektedir. Bu sonuçlara göre 300 kWh'lik bir On-grid güneş enerjisi sisteminin başlangıç maliyetinin 2016 yılına göre \%35 oranında düştüğü söylenebilir. Ayrıca Haziran 2021 verilerine göre sistemden yıllık yaklaşık 50000 \$ (428000 / 8.60) gelir elde edilmesi, sistemin Akdeniz Bölgesi güneş enerjisi sisteminin getiri beklentileri ile uyumlu olduğunu göstermektedir.

Araştırma konusu işletme, lisanssız elektrik üretimi yapan tesisler kategorisinde olup lisanslı elektrik üretimi yapan tesislerde alım fiyatları farklılık göstermektedir. Yenilenebilir Enerji Kaynak belgeli üretim tesisleri için uygulanacak YEK Destekleme Mekanizması (YEKDEM) alım ve yerli katkı fiyatları ile uygulama süreleri 30 Ocak 2021 tarihinde Resmi Gazetede yayımlanan karar ile 1 Temmuz 2021 sonrasında YEKDEM kapsamında uygulanacak alım fiyatları güncellenmiştir (Anonim, 2021f). Buna göre, 1 Temmuz 2021'den 31 Aralık 2025'e kadar işletmeye girecek YEK belgeli üretim tesisleri için uygulanacak alım fiyatı rüzgâr veya güneş enerjili elektrik üretimi tesisi için $0.32 \mathrm{TL} \mathrm{kWh}^{-1}$ olarak belirlenmiştir. Bu tesisler için YEKDEM alım fiyatı uygulama süresinin $10 \mathrm{yıl}$, yerli katkı fiyatının $0.08 \mathrm{TL} \mathrm{kWh}^{-1}$, yerli katkı uygulama süresinin ise 5 yıl olmasına karar verilmiştir. Açıklanan bu fiyatlar lisanslı elektrik üretim tesisleri için geçerlidir. Lisanssız tesisler için enerjinin satın alım garantisi işletmeye girilmesi itibari ile 10 yıldır ve bu tesislerde yerli katkı payı uygulanmamaktadır (Anonim, 2021g).

\section{Tatı su balık (off-grid) işletmesi PV sistemi ve maliyet analizi}

Güneş enerjisinden üretilen elektrik enerjisinin sadece işletme içerisinde kullanıldığı bu sistemde güneş panelleri, akü grubu, akü şarj regülatörü, invertör ve yardımcı elektronik devreler bulunmaktadır. Tesisin günlük enerji ihtiyacı kurulan bu $\mathrm{PV}$ sistemden karşılanırken, güneşin olmadığı gece saatlerinde ya da bulutlu günlerde enerjisiz kalmamak için akü grubu sisteme enerji vermektedir. Sistemde sorun yaşanması 
durumunda ise dizel jeneratör devreye girmektedir.

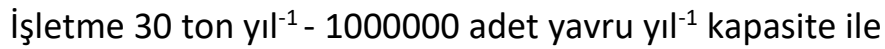
çalışmakta, şebeke bağlantısı olmadığı için elektrik enerjisinin tamamını yenilenebilir enerji kaynağı PV sistemlerden karşılamaktadır. GEPA'ya göre Kahramanmaraş'ın günlük ortalama güneşlenme süresi 8 saat, günlük gelen güneş enerjisi $4.41 \mathrm{kWh} \mathrm{m}^{-2}$ gün olduğu tespit edilmiştir. Ancak bu değerler havanın temiz ve güneş açısının dik olduğu zamanlar için geçerlidir. Bu nedenle kayıpların yaşanacağı ve güneşlenme süresinin çok daha az olduğu kış ayları da dikkate alınarak günlük $232 \mathrm{~kW}$ enerji gereksinimi olan tesisin ihtiyacını karşılamak için 49 kWh'lik üretim yapan bir güneş paneli sistemi tasarlanmıştır. Tesisin kış ayları temel alınarak günlük ortalama 4 saat güneş aldığı kabul edilirse 245 kW'Iık (49 x 5) enerji elde edilmesi beklenmektedir. Bu enerji ihtiyacının karşılanabilmesi için 192 adet 255 W değerinde panel dizisi kullanılmıştır. Panel sayısı belirlenirken çatı alanının kısıtlayıcı etkisi de göz önüne alınmıştır. Sistemin aynı anda 15 kW'ık kısmının çalışacağı düşünülerek 15 kW'lık invertör, 60 amperlik 11 adet akü şarj regülatörü ve $230 \mathrm{~kW} \mathrm{~h}^{-1}$ l'lk enerjiyi depolayabilecek 2 V 1200 Ah'lik 96 adet akü grubu kullanılmıştır. Sistemde kullanılan diğer ekipmanlar solar kablolar, bağlantı elemanları ve sigortalardır. Günlük ortalama 245 kW'lık enerji üretebilen tatlı su balık işletmesinde uygulanan PV sistem için maliyet hesabı Çizelge 9'da gösterilmiştir.

Çizelge 9. Tatlı su balık işletmesi PV sistemde kullanılan ekipmanların maliyetleri

Table 9. Cost of the equipment used in the freshwater fish enterprise PV system

\begin{tabular}{llccc}
\hline PV sistem elemanı & \multicolumn{1}{c}{ Özellikler } & $\begin{array}{c}\text { Miktar } \\
\text { (Adet) }\end{array}$ & $\begin{array}{c}\text { Birim fiyat } \\
\text { (\$) }\end{array}$ & $\begin{array}{c}\text { Toplam fiyat } \\
\text { (\$) }\end{array}$ \\
\hline Güneş paneli & Polikristal 255 W & 192 & 110 & 21120 \\
Akü & Endüstriyel tip 2V,1200Ah & 96 & 250 & 24000 \\
Şarj regülatörü & 60 Amper MPPT & 11 & 310 & 3410 \\
İnvertör & 5000 W & 3 & 1000 & 3000 \\
Diğer ekipmanlar & Kablo, bağlantı elemanları, sigortalar vb. & 1 Grup & 3500 & 3500 \\
Toplam maliyet & & & & 55030 \\
\hline
\end{tabular}

Bu tesiste güneş enerjisi sistemi kurulmadan önce enerji ihtiyacı 20 kVA gücündeki dizel jeneratör tarafından karşılandığı bildirilmiştir. Tam yükte çalışırken günlük yaklaşık $40 \mathrm{~L}$ dizel akaryakıt kullanan bu jeneratörün günlük maliyeti Haziran 2021 tarihi itibari ile 292 TL (40 x 7.3) olmaktadır. Tüm yıl kullanıldığı düşünüldügünde 106580 TL (365 x 292) yıllık maliyet olmaktadır. Haziran 2021 dolar kuru ortalama 8.60 TL olduğu düşünüldüğünde, sistem maliyeti 473000 TL $(55000 \mathrm{x}$ 8.60) olmaktadır (Çizelge 9). Tesisin maliyetinin yaklaşık 473000 TL olduğu ve tam yükte çalıştığı düşünülürse 4.4 yılda (473000 / 106580) başa başnoktasını yakaladığı ve kendisini amorti ettiği belirlenmiştir.

Yenilenebilir enerji kaynaklarından güneş enerjisinin tek başına kullanımında karşılaşılan süreksizlikler ve gece saatlerinde kesintiye uğraması nedeniyle, rüzgâr enerjisi ile birlikte kullanılmasının yenilenebilir enerji sistemlerini daha verimli ve güvenilir hale getirdiği belirtilmiştir. Birden fazla yenilenebilir enerji kaynağının birlikte kullanıldığı bu hibrit enerji sistemlerinin hangilerinin birlikte uygulanacağının bölgenin meteorolojik koşullarına göre belirleneceği açıklanmıştır (Kurban ve Hocaoğlu, 2004). Buna göre araştırma konusu tatlı su balık işletmesi gibi şebekeden bağımsız yenilenebilir enerji sistemleri kullanan tarımsal işletmelerde, enerji gereksiniminin kesintiye uğramaması ve aküleme maliyetinin daha aşağılara çekilmesi açısından hibrit uygulamaları kullanımının bir gereklilik olduğu sonucuna ulaşılmıştır.

Elektrik enerjisini dizel jeneratör ile karşılayan bir telefon baz istasyonunda hibrit yenilenebilir enerji kullanımının uygulanabilirliğinin ve geri ödeme süresinin konu edildiği bir araştırmada, işletme ve bakım maliyetleri de göz önüne alınarak hibrit sistemin geri ödeme süresinin 2 ile 4 yıl arasında olduğu, ayrıca hibrit sistem kullanımı ile dizel yakıt kullanımının \%70-80 oranında düştüğü, dolayısıyla $\mathrm{CO}_{2}$ salınımının azaldığı ve çevre dostu bir sistem olduğu ifade edilmiştir (Nema ve ark., 2010). Buna göre araştırmanın yürütüldüğü tatlı su balık işletmesinde kullanılan PV güneş enerjisi sisteminin 4.4 yıl olan geri ödeme süresinin hibrit bir sistem ile benzerlik arz ettiği ve tesise eklenecek rüzgâr enerjisi sisteminin maliyeti artıracağı ancak daha az batarya kullanımı gerektireceğinden, geri ödeme süresinin fazla bir değişikliğe uğramayacağı düşünülmektedir.

PV sistem elemanları için piyasada çok farklı markalar mevcuttur ve farklı fiyatlar oluşabilmektedir. İşletmelerin büyüklüğüne, pazarlık gücüne ve rekabet koşullarına göre fiyatlar değişebilmektedir. Araştırmada ele alınan her iki işletmenin de PV sisteminin maliyetleri, 
yapıldıkları dönemdeki anlaşmaları göz önünde bulundurularak dolar üzerinden hesaplanmıştır.

Kahramanmaraş ilinde bulunan iki farklı hayvancılık işletmesinde (etlik piliç ve tatlı su balık işletmesi) mevcut bulunan fotovoltaik (PV) enerji sistemlerinin incelendiği bu araştırmadan elde edilen sonuçlar ve öneriler aşağıdaki gibi özetlenebilir:

Bölgenin güneş enerjisi potansiyeli ve her bir işletmenin enerji gereksinimleri dikkate alınarak yapılan hesaplamaların sonucunda etlik piliç işletmesinde kullanılan On-grid PV sistemde güneş panellerinin ürettiği $300 \mathrm{kWh}$ elektrik enerjisi invertör ve çift yönlü sayaç ile şebeke hattına verilmiştir. İşletmenin ihtiyacı olan elektrik enerjisi ve üretilen elektrik enerjisi arasındaki fark, işletmeye kazanç olarak kaydedilmiştir. Sistemin geri ödeme süresi yaklaşık 4 yıl olarak hesaplanmıştır. Tarım ve hayvancılık işletmelerine sağlanan Tarım ve Orman Bakanlığı ve bağı kuruluşlar bünyesinde verilen hibe desteğinden yararlanılması durumunda ise başa başnoktasının yakalanması 2-3 yıl arasında olmaktadır. On-grid PV sistem kullanan etlik piliç işletmesi, üretilen fazla elektriğini şebekeye verdiğinden, buradan yaklaşık $312000 \mathrm{TL} \mathrm{yıl}^{-1}$ gelir elde etmektedir.

Tatlı su balık işletmesinde 49 kWh kapasiteli güneş panelinden oluşan Off-grid PV sistemi ile elektrik enerjisi üretilmiştir ve bu enerji $2 \mathrm{~V} 1200$ Ah akülerde depolanmıştır. Aküler 24'lük gruplar halinde 4 grup seri ve paralel bağlanarak sistem voltajı $48 \mathrm{~V}$ DC olacak şekilde düzenlenmiştir. İnvertör aracılığı ile de sistemin ihtiyacı olan AC elektrik enerjisine dönüştürülerek kullanılmıştır. Yapılan ekonomik analizde, şebekeden uzak yerlerde kullanılan PV sisteminin dizel jeneratörlere oranla daha avantajlı olduğu ve basit geri ödeme süresinin ortalama 4-5 yıl olduğu tespit edilmiştir. Tarım ve Orman Bakanlığı desteği ile birlikte geri ödeme süresi ise 2-3 yıl arasında olmaktadır.

Kahramanmaraş, güneş ışııı şiddeti ve güneşlenme süresi açısından, Türkiye ortalamasının üstünde değerlere sahiptir. Ancak şebekeden bağımsız (Off-grid) bir işletmede güneş panellerine kış aylarında gelen enerjinin yetersiz olacağı ve geceleri güneş enerjisinden faydalanılamayacağından dolayı, sadece güneş panelleriyle üretilecek enerjinin yeterli olmayacağı, sisteme dâhil edilecek bir rüzgâr türbini yardımı ile hibrit bir sistem üzerinden planlamanın yapılması ile daha iyi sonuçlar alınacağı düşünülmektedir.

Araştırma konusu her iki hayvancılık işletmesi için kullanılan güneş panellerinin, şarj regülatörü ve evirici gibi cihazların pek çoğunun ithal ve göreceli olarak hala pahalı olmaları nedeniyle ilk yatırım maliyetlerinin yüksek olduğu düşünülebilir. Ancak PV sistemleri 10 yıl bozulmama garantisi ve 20 yıl çalışma garantisi ile satılmaktadır. Ayrıca, bu sistemlerin bakım masrafları da yok denecek kadar azdır. Çalışma ömürlerinin 20 yıl olduğu düşünüldüğünde geri ödeme sürelerinin düşük ve sistemin ekonomik açıdan uygulanabilir olduğu görülmektedir.

Tarımsal ve kırsal alanlardaki hayvancılık işletmelerine devlet tarafından uygulanan teşvikler dikkate alındığında, yatırımın türüne göre $\% 50$ ila $\% 70$ arasında hibe desteklerinin olması, geri ödeme sürelerini en az \%50 oranında düşürmektedir. Bu destekler sayesinde tarım ve hayvancılık işletmelerinin en büyük giderlerinden biri olan elektrik enerjisi maliyetlerini sıfırlaması ve ilk yatırım maliyetlerini çok daha kısa sürede sağlamasıdır.

Hayvancılık işletmelerinde kullanılan yenilenebilir enerji kaynaklarından PV güneş enerjisi sistemlerinin, ekonomik ve işletmelere kâr sağlayıcı olmasının yanı sıra, fosil yakıtlardan kaynaklı sera gazı emisyon değerlerinin düşürülmesine ve daha temiz bir gelecek bırakma misyonuna önemli katkı sağlayacağı da bir gerçektir.

$\mathrm{Bu}$ sonuçlar doğrultusunda yapılacak öneriler ise aşağıdaki şekilde sıralanabilir;

Tarım ve hayvancllık işletmelerinde güneş ve rüzgâr enerjisinden elektrik üretimi ve kullanımının yaygınlaşması ve bu amaç doğrultusunda öncelikle tarım sektöründe yenilenebilir enerji bilincinin artırılması sağlanmalıdır. Sektör temsilcileri ve potansiyel yatırımcılar için bilgilendirme toplantıları yapılarak, konunun ülke ve işletmelerin geleceği üzerindeki etki ve avantajları anlatılmalıdır. Hayvancılık işletmelerinde PV güneş sistemi kuracak işletmelere, teknik altyapı ve resmi işlemlerinde kolaylık sağlanarak prosedür yükleri hafifletilebilir. Tarım ve hayvancılık işletmelerine verilen yenilenebilir enerji hibe desteklerinin artarak devam etmesi ve yatırımların uygulanabilir olması açısından yenilenebilir enerji sistemlerinin kurulumunda kullanılan malzemelerin ithalatında vergi muafiyetleri sağlanabilir. Yenilenebilir enerji yatırımlarının yaygınlaşabilmesi için ilk kurulum maliyetinin düşmesi ve güneş paneli üretim teknolojilerinin gelişmesi ve daha ekonomik yollardan üretilmesi gerekmektedir. Dünyada olduğu gibi ülkemizde de yenilenebilir enerjinin gelişimi, genel olarak kamu tarafindan sunulan destekleme yöntemlerinin etkinliğine göre yön bulmaktadır. Bu nedenle, çoğunluğu ithal olarak ülkemize giren bu teknolojilerin daha ucuza mal edilebilmesi için, yerli üretimin devlet tarafından desteklenmesi çok büyük önem arz etmektedir. Yenilenebilir enerji endüstrisindeki Ar-Ge çalışmalarına verilen destek artarak devam etmelidir.

Tarım ve hayvancılık sektörünün gelişimi için 
yenilenebilir enerji kaynaklarına teşvikler verilirken bu sistemlerin ülke imkânları ile üretilme durumları da dikkate alınmalıdır. Aksi halde teşvik olarak devlet tarafından ayrılan bütçeler yabancı ülkelere kaynak oluşturabileceği unutulmamalıdır.

Enerjide dışa bağımlı bir ülke olan Türkiye'de elektrik enerjisi tüketiminde her yıl \%6'।ık bir artış olmaktadır. Bu yükselmede nüfus artışı ve sanayileşme ile birlikte artan gıda talebi de önemli rol oynamaktadır. Fosil yakıtların giderek azaldığı, iklim değişikliği ve hava kirliliğinin arttığı bir dönemde, yenilenebilir enerji kaynaklarına ağırlık verilerek geliştirilmesi ve ülke öz kaynaklarının daha etkili bir şekilde kullanımını sağlayacak tarım politikaları ve projelere öncelik verilmesi gerekmektedir. Enerji birim maliyetleri hesaplanırken çevreye verilen toplam zarar da değerlendirilmeli, sürdürülebilir tarım ve hayvancılık bilinci ile enerji alanında bu sorumlulukla adımlar atılmalıdır.

Türkiye'de enerji kullanımı ve enerji verimliliği konusuna bir bütün olarak bakıldığında, daha ekonomik ve sürdürülebilir yenilenebilir enerji kaynaklarına yatırım yapmanın yanı sıra, enerjide kayıpların azaltılması ve elde edilen enerjinin daha verimli kullanılabilmesi de önemli bir yer tutmaktadır. Sanayide olduğu kadar tarım ve hayvancilık faaliyetlerinde bulunan işletmelerde kullanılan elektrikli ekipmanların seçiminde de enerji verimliliğinin ön planda tutulması ve hali hazırda kısıtlı olan enerji kaynaklarının daha dikkatli kullanılması, enerji yönetimi konusunda dikkate alınması gereken önemli etkenler olmaktadır.

\section{ÖZET}

Amaç: Bu çalışmanın amacl, Kahramanmaraş ilinde bulunan iki farklı hayvancılık işletmesinde (etlik piliç ve tatlı su balık işletmesi) mevcut bulunan şebekeye bağlantılı (On-grid) ve şebekeye bağlantısız (Off-grid) fotovoltaik (PV) enerji sistemlerinin kullanımını değerlendirmektir.

Yöntem ve Bulgular: İşletmelerin kurulu güçlerine göre elektrik enerjisi gereksinimleri belirlenerek PV sistem ekipmanları ve özellikleri incelenmiş, enerji (elektrik ve akaryakıt) maliyetleri belirlenmiş ve ekonomik analizi yapılmışır. İşletmelerin enerji gereksinimlerine uygun sistem tasarım ve maliyetlerinin incelendiği araştırma sonucunda, $300 \mathrm{kWh}$ kapasiteli etlik piliç işletmesi ve 49 kWh kapasiteli tatlı su balık işletmesinin her biri 4 ila 5 yıl içerisinde başa başnoktasına ulaşmakta ve elektrik enerjisi maliyetlerini sıfıra indirgemektedirler. Ancak Ongrid sistem kullanan etlik piliç işletmesi üretilen fazla elektriğini şebekeye verdiğinden, buradan yaklaşık $312000 \mathrm{TL} \mathrm{yIl}^{-1}$ gelir elde etmektedir. PV güneş sistemi kullanım ömürlerinin 20 yıl olduğu düşünüldüğünde, tarım ve hayvancılık işletmelerinde kullanımlarının son derece kârlı olduğu görülmektedir.

Genel Yorum: Türkiye, güneş enerjisindeki potansiyel üstünlüğüne rağmen tarımsal üretimde bu potansiyelden yeterince yararlanamadığından bu alanda üretilen enerji toplam enerji ihtiyacının çok altında kalmaktadır. Bunun en büyük nedeni fotovoltaik (PV) enerji sistemlerinin başlangıç maliyetlerinin enerji verimliliğine oranla yüksek olmasıdır.

Çalışmanın Önemi ve Etkisi: Tarım ve hayvancılık sektöründe enerji ihtiyacı ve maliyetleri gün geçtikçe artmakta ve önemli bir sorun haline gelmektedir. Bu maliyetlerin azaltılması için çiftliklerde güneş ve rüzgâr enerjisinden elektrik üretimi yaygınlaşmaktadır. Araştırmanın, tarım ve hayvancılık alanında PV güneş enerjisi sistemlerinin kullanılması ile enerji yönetimi ve enerji çeşitliliği açısından örnek olacağı düşünülmektedir.

Anahtar Kelimeler: : Enerji, fotovoltaik (PV), etlik piliç işletmesi, tatlı su balık işletmesi.

\section{TEŞEKKÜR}

Yazarlar araştırma materyali olarak seçilen hayvancılık işletmeleri yetkililerine, sağladıkları desteklerden dolayı teşekkür ederler.

\section{ÇIKAR ÇATIŞMA BEYANI}

Makale yazarları aralarında herhangi bir çıkar çatışması olmadığını beyan ederler.

\section{ARAŞTIRMACILARIN KATKI ORANI BEYANI}

Yazarlar makaleye eşit oranda katkı sağlamış olduklarını beyan ederler.

\section{KAYNAKLAR}

Akyüz E, Bayraktar M, Oktay Z (2009) Hibrid yenilenebilir enerji sistemlerinin endüstriyel tavukçuluk sektörü için ekonomik açıdan değerlendirilmesi: Bir uygulama. Balıkesir Üniversitesi FBE Dergisi 11(2): 4454.

Anonim (2021a) Coğrafi yapı Kahramanmaraş. http://www.kahramanmaras.gov.tr/cografi-yapi (Erişim tarihi, 20.03.2021).

Anonim (2021b) Traksiyoner akü. http://blog.inciaku.com/traksiyoner-aku-nedir/ (Erişim tarihi, 24.03.2021).

Anonim (2021c) Şebeke bağlantılı (ON-GRiD) sistemler. http://www.bnmsolar.com/?pnum=\%2010\&pt (Erişim tarihi, 26.03.2021). 
Anonim (2021d) Güneş enerjisi santrallerinin kurulumu ve maliyeti. https://www.eneriibes.com/gunesenerii-santrali-kurulumu-maliyeti/ (Erişim tarihi, 10.04.2021).

Anonim (2021e) Güneş enerjisi santrali maliyet, gelir ve kazanç örnekleri. https://www.enerjibes.com/guneseneriisi-santrali-kazanc/ (Erişim tarihi 13.04.2021).

Anonim (2021f) Resmi Gazete. https://www.resmigazete.gov.tr/fihrist?tarih=202101-30 (Erişim tarihi, 21.06.2021).

Anonim (2021g) Entegro enerji sistemleri. Yenilenebilir enerjide yeni alım fiyatları. http://entegro.com.tr/yeni-alim-fiyatlari-2021/ (Erişim tarihi 22.06.2021).

Behçet R, Oral H, Gül H (2013) Adıyaman ilinin güneş enerjisi potansiyeli ve kullanımı. Batman Üniversitesi Yaşam Bilimleri Dergisi 3(2): 52-67.

Bilgili ME, Dağtekin M (2017) Fotovoltaik piller ile elektrik üretiminde uygun eğim açısının ve yıllık oluşan enerji farkının belirlenmesi. Gaziosmanpaşa Bilimsel Araştırma Dergisi 6: 156-167.

Dağtekin $M$ (2012) Etlik piliç kümeslerinin serinletilmesinde güneş enerjisi kullanımının teknoekonomik analizi. Çukurova Üniversitesi Ziraat Fakültesi Dergisi 27(2): 11-20.

Dağtekin M, Kaya D, Öztürk HH, Kılıç FÇ (2014) A study of techno-economic feasibility analysis of solar photovoltaic $(\mathrm{PV})$ power generation in the province of Adana in Turkey. Energy Exploration \& Exploitation 32(4): 719-735.

Eker B, Vardar A (2004) Küçük rüzgâr türbinlerinin tarımsal işletmelerde kullanılabilme olanakları. V. Ulusal Temiz Enerji Sempozyumu, 26-28 Mayıs, İstanbul.
EPDK (Enerji Piyasası Düzenleme Kurumu) (2021) Elektrik faturalarına esas tarife tabloları. https://www.epdk.gov.tr/Detay/Icerik/31327/elektrik-faturalarina-esas-tarife-tablolari (Erişim tarihi, 12.04.2021)

ETKB (Enerji ve Tabii Kaynaklar Bakanlığı) (2021) Güneş enerjisi potansiyel atlası (GEPA) Kahramanmaraş. https://gepa.enerji.gov.tr/MyCalculator/pages/46.as px (Erişim tarihi, 10.04.2021)

Karaca C (2017) Hatay ilinin hayvansal gübre kaynağından üretilebilir biyogaz potansiyelinin belirlenmesi. Mustafa Kemal Üniversitesi Ziraat Fakültesi Dergisi 22(1): 34-39.

Karaca C (2019) Agricultural residues potential of Hatay. Mustafa Kemal Üniversitesi Tarım Bilimleri Dergisi (Özel Sayı) 24: 9-15.

Kurban M, Hocaoğlu FO (2004) Anadolu Üniversitesi İki Eylül Kampüsü'nde rüzgâr ve güneş potansiyelini belirleyerek hibrid (rüzgâr-güneş) enerji santral modeli kurmak. Bilimsel Araştırma Projesi, Anadolu Üniversitesi, Eskişehir.

Nema P, Nema RK, Rangnekar S (2010) Minimization of green house gases emission by using hybrid energy system for telephony base station site application. Renewable and Sustainable Energy Rewievs 16351639.

Öztürk HH, Yaşar B, Eren Ö (2010) Tarımda enerji kullanımı ve yenilenebilir enerji kaynakları. Türkiye Ziraat Mühendisliği VII. Teknik Kongresi, 11-15 Ocak, Ankara. 